\title{
Do stocking densities affect the gut microbiota of gibel carp Carassius auratus gibelio cultured in ponds?
}

\author{
Z. $\mathrm{Zhou}^{1 *}$, S. $\mathrm{He}^{1}$, Y. Liu ${ }^{1}$, P. Shi' ${ }^{1}$, B. Yao ${ }^{1}$ and E. Ring $\varnothing^{2}$
}

${ }^{1}$ Key Laboratory for Feed Biotechnology of the Ministry of Agriculture, Feed Research Institute, Chinese Academy of Agricultural Sciences, Beijing 100081, P. R. China ${ }^{2}$ Norwegian College of Fishery Science, Faculty of Biosciences, Fisheries and Economics, University of Tromsø, 9037 Tromsø, Norway

\begin{abstract}
The aim of the present study was to evaluate the intestinal microbial communities of gibel carp (Carassius auratus gibelio) cultivated in two beach ponds at different stocking densities. The two ponds were both $\sim 3.33 \mathrm{hm}^{2}$ in acreage and $\sim 1.5 \mathrm{~m}$ in depth. The stocking densities included one intensive with 2 fish $\mathrm{m}^{-3}$ while the other treated as semi-intensive with 1 fish $\mathrm{m}^{-3}$. The gut microbiota (both allochthonous and autochthonous) were sampled after 135 days of feeding. Denaturing gradient gel electrophoresis (DGGE) of PCR-amplified 16S rRNA gene segments was used to evaluate the bacterial community. Actinobacteria, Cyanobacteria, Firmicutes, Fusobacteria, Proteobacteria and some unclassified_bacteria taxa were identified in gut samples and feed. Similar bacterial communities $\left(C_{s}=0.83\right)$ were observed with respect to the autochthonous and allochthonous gut microbiota of gibel carp cultured in the intensive culture pond. In contrast to these results, some difference $\left(C_{s}=0.61\right)$ was observed in the gut microbiota of fish reared in the semi-intensive culture pond. Our results indicated that the difference in the bacterial communities between allochthonous bacteria and gut associated bacteria of gibel carp was not constant and was modulated by the stocking density.
\end{abstract}

Keywords: Beach pond; Carassius auratus gibelio; Gut microbiota; Stocking density

\section{Introduction}

In order to expand aquaculture production, the increase in stocking density is of high importance because the cultured area in China has decreased from 7,281,252 ha to $6,549,932$ ha from 2004 to 2008 [1]. However, it has been reported that higher stocking density could affect the production and nutritional status, health and stress indicators of the fish $[2,3]$. There are present of many bacteria that have adhered to the mucosal surface of the intestine which may contribute to indigenous microbiota called autochthonous microbiota [4]. These microbiota play an important role in the health and disease control of fish, which is also affected by the developmental stages, diet and environmental conditions [4-6]. The composition of the Atlantic salmon gut microbiota was sensitive to diets with cellulose or non-strach polysaccharides from soybean meal [7]. The intestinal bacterial flora of hybrid tilapia cultured in earthen ponds varied with seasonal change, the highest total viable counts of bacteria were appeared in autumn, Pseudomonas spp. were found only in winter, other bacteria Photobacterium damselae, Pasteurella spp., Cellulomomus sp. and Bacillus sp. were present in some seasons of the year [8]. Dietary supplementation with $\mathrm{Cu}^{2+}$-exchanged montmorillonite significantly reduced $(\mathrm{P}<0.05)$ the total intestinal aerobic bacterial counts and affected the composition of intestinal microflora with a tendency of Aeromonas, Vibrio, Pseudomonas, Flavobacterium, Acinetaobacteria, Alcaligence, Enterobacteriaceae decreasing as compared with control [9].

One of the traditional cultured fish species in China, gibel carp (Carassius auratus gibelio) is well adapted to varying culture conditions and have therefore received much attention [7]. In an early study, $\mathrm{He}$ et al. [8] showed that higher stocking density impaired growth and feed conversion of gibel carp cultured in cages, which might be due to low utilization efficiency of nitrogen and energy [9]. However, to our knowledge, no information is available about modulation of the intestinal microbiota of fish reared at different stocking densities. Such effect might be related to disease control [10-12]. The relationship between high stocking density and increased disease incidence has previously been suggested [13]. Bullock et al. [14] put forward the hypothesis that reduction in stocking density could improve disease resistance. The main purpose of the present study was to evaluate the intestinal microbial communities of gibel carp cultivated in ponds at two different stocking densities. In order to obtain reliable information about the gut microbiota both allochthonous and autochthonous microbiota were investigated.

\section{Materials and Methods}

\section{Sample preparation}

Two saline-alkali beach ponds, along the East Sea of China, located in Yancheng City, Jiangsu Province, China were used. Each pond was $\sim 3.33 \mathrm{hm}^{2}$ in acreage, $\sim 1.5 \mathrm{~m}$ in depth, $\mathrm{pH} 8.5$ and $2 \%$ salinity. Both ponds were mono-cultured with gibel carp fed similar commercial diet (crude protein level, 33\%; Jiangsu Nanshan Feed Co., Ltd, China) under identical situations except for the stocking density. Initial body weight ( $\sim 50 \mathrm{~g})$, feeding frequency ( 4 meals per day) and feeding time (08:00, 11:00, 15:00, and 18:00) were similar in both ponds. The fish were continuously fed for 45 minutes until almost all individuals ceased feeding. Aeration was carried out for 3 hours from 12:00 to 15:00. In one pond the stocking density was $\sim 2$ fish $\mathrm{m}^{3}$ (HD) while the stocking density was $\sim 1$ fish $\mathrm{m}^{3}$ (LD) in the 2 nd pond. These values represent intensive - and semi - intensive culture ponds in China [15]

*Corresponding author: Z. Zhou, Key Laboratory for Feed Biotechnology of the Ministry of Agriculture, Feed Research Institute, Chinese Academy of Agricultural Sciences, No.12 Zhongguancun South Street, Beijing 100081, P. R. China, Tel. +8610 82106073; Fax.+8610 82106054; E-mail: zhou_zg@msn.com

Received June 30, 2011; Accepted August 22, 2011; Published September 10 2011

Citation: Zhou Z, He S, Liu Y, Shi P, Yao B, et al. (2011) Do stocking densities affect the gut microbiota of gibel carp Carassius auratus gibelio cultured in ponds? J Aquac Res Development S1:003. doi:10.4172/2155-9546.S1-003

Copyright: ( 2011 Zhou Z, et al. This is an open-access article distributed under the terms of the Creative Commons Attribution License, which permits unrestricted use, distribution, and reproduction in any medium, provided the original author and source are credited. 
Citation: Zhou Z, He S, Liu Y, Shi P, Yao B, et al. (2011) Do stocking densities affect the gut microbiota of gibel carp Carassius auratus gibelio cultured in ponds? J Aquac Res Development S1:003. doi:10.4172/2155-9546.S1-003

Page 2 of 5

\begin{tabular}{llllll}
\hline & Auto-HD & Auto-LD & Allo-HD & Allo-LD & Feed \\
\hline Auto-HD & 1.00 & & & & \\
Auto-LD & $0.86 \mathrm{~ns}$ & 1.00 & & & \\
Allo-HD & $0.83 \mathrm{~ns}$ & $0.81 \mathrm{~ns}$ & 1.00 & 1.00 & $0.58^{* *}$ \\
Allo-LD & $0.53^{* *}$ & $0.61^{*}$ & $0.44^{* *}$ & $0.42^{* *}$ & 1.00 \\
Feed & $0.50^{* *}$ & $0.47^{* *}$ & .
\end{tabular}

*Auto-HD: autochthonous gut microbiota of gibel carp cultivated at the high stocking density; Auto-LD: autochthonous gut microbiota of gibel carp cultivated at the low stocking density; Allo-HD: allochthonous gut microbiota of gibel carp cultivated at the high stocking density; Allo-LD: allochthonous gut microbiota of gibel carp cultivated at the low stocking density; Feed: microbiota of the diet.

${ }^{\dagger} C_{s}<0.60$ is regarded as significant difference; $0.6 \leq C_{s}<0.80$ is marginal difference; and $C_{s} \geq 0.80$ is similar. ${ }^{* *}$ - significantly different; ${ }^{*}$ - marginally different; ns - similar

Table 1: Pairwise similarity coefficient $\left(C_{s}\right)$ matrix of bacterial communities in the gastrointestinal $(\mathrm{Gl})$ tract of gibel carp (Carassius auratus gibelio) cultivated in two salinealkali ponds of Eastern China at different stocking density and in the feed.

\begin{tabular}{|c|c|c|c|c|c|c|c|c|c|}
\hline \multirow{2}{*}{$\begin{array}{l}\text { Phylogenetic } \\
\text { group }\end{array}$} & \multirow{2}{*}{ Band no. } & \multirow{2}{*}{ Closest relative (obtained from BLAST search) } & \multirow{2}{*}{ Identity (\%) } & \multirow{2}{*}{ Accession no. } & \multicolumn{5}{|c|}{ Relative abundance $(\mathrm{RA}, \%)^{\dagger}$} \\
\hline & & & & & Auto-HD & Auto-LD & Allo-HD & Allo-LD & Feed \\
\hline \multirow[t]{3}{*}{ Actinobacteria } & 9 & Uncultured Actinobacterium (AY795724.2) & 95 & EU585899 & 0.5 & 0.1 & 2.4 & 1.4 & - \\
\hline & 41 & Uncultured Corynebacterium sp. (EU029393.1) & 100 & EU585931 & 3.5 & 4.1 & 6.7 & 8.5 & - \\
\hline & 11 & Uncultured Rubrobacterales bacterium (EF662655) & 95 & EU585901 & 3.6 & 1.6 & - & 2.2 & 1.6 \\
\hline \multirow[t]{8}{*}{ Proteobacteria } & 7 & Acinetobacter sp. (EU260356.1) & 100 & EU585896 & - & - & - & - & 2.5 \\
\hline & 43 & Uncultured Acinetobacter sp. (EU704874.1) & 99 & EU585929 & - & - & - & 1.2 & - \\
\hline & 17 & Uncultured Eubacterium sp. (AM422244.1) & 98 & EU585907 & - & - & - & - & 2.6 \\
\hline & 18 & Uncultured Eubacterium sp. (AM422244.1) & 98 & EU585908 & - & - & - & - & 1.4 \\
\hline & 37 & Uncultured Eubacterium sp. (AM422244.1) & 99 & EU585928 & - & - & 2.7 & 3.6 & - \\
\hline & 15 & Uncultured gamma Proteobacterium (DQ676291.1) & 98 & EU585905 & - & - & - & 1.3 & - \\
\hline & 16 & Uncultured gamma Proteobacterium (DQ676291.1) & 98 & EU585906 & - & - & - & 1.7 & 2.9 \\
\hline & 34 & Uncultured Proteobacterium (EF664750.1) & 98 & EU585925 & - & - & - & - & 11.2 \\
\hline \multirow[t]{10}{*}{ Firmicutes } & 12 & Clostridium bifermentans (EU887825.1) & 98 & EU887825 & 2.6 & 12.7 & 7.9 & 5.1 & 3.1 \\
\hline & 19 & Clostridium bifermentans (EU887825.1) & 100 & EU585909 & - & - & - & 10.4 & - \\
\hline & 20 & Clostridium bifermentans (EU887825.1) & 98 & EU585910 & 0.5 & 1.4 & 1.9 & 9.0 & - \\
\hline & 22 & Clostridium paraputrificum (AY442815.1) & 98 & EU585913 & - & - & - & 1.2 & - \\
\hline & 29 & Exiguobacterium sp. ( EF101987.1) & 100 & EU585903 & - & 1.7 & - & 1.0 & - \\
\hline & 40 & Lactobacillales bacterium (EU728748.1) & 99 & EU585930 & 3.0 & 5.8 & 2.8 & - & - \\
\hline & 3 & Lactobacillus panis (EF412978.1) & 100 & EU585895 & 1.2 & 3.7 & - & 0.9 & - \\
\hline & 42 & Lactococcus garvieae (EU727199.1) & 99 & EU585927 & 24.6 & 33.1 & 16.0 & 19.4 & 4.7 \\
\hline & 36 & Streptococcus infantarius (AJ439568) & 100 & EU585923 & 2.0 & - & 3.0 & - & - \\
\hline & 2 & Uncultured Firmicutes bacterium (AB451793.1) & 99 & EU585891 & 10.0 & 6.1 & 15.4 & - & 12.8 \\
\hline \multirow[t]{4}{*}{ Fusobacteria } & 6 & Anaerobic bacterium G13(AB064328) & 96 & EU585894 & - & - & - & 5.6 & 8.5 \\
\hline & 1 & Cetobacterium somerae (AB353124.1) & 100 & EU585890 & 24.2 & 2.2 & 15.9 & 2.2 & 4.4 \\
\hline & 5 & Fusobacteria bacterium (AY579753.1) & 97 & EU585893 & _- & 2.7 & 2.6 & 4.4 & 0.5 \\
\hline & 4 & Uncultured microorganism (EU181077.1) & 99 & EU585892 & 7.6 & - & 7.9 & 1.7 & 10.5 \\
\hline \multirow[t]{2}{*}{ Cyanobacteria } & 30 & Uncultured bacterium (AB254251.1) & 98 & EU585922 & 4.3 & 8.5 & 2.5 & 4.9 & 4.0 \\
\hline & 31 & Uncultured bacterium (AB254251.1) & 100 & EU585924 & - & - & 1.2 & 0.8 & - \\
\hline \multirow[t]{9}{*}{$\begin{array}{l}\text { Unclassified_ } \\
\text { Bacteria }\end{array}$} & 27 & Vaccinium corymbosum (DQ445025.1) & 94 & EU585919 & - & - & - & 2.5 & - \\
\hline & 35 & Uncultured Actinobacterium (DQ676371.1) & 99 & EU585920 & - & - & - & - & 1.7 \\
\hline & 10 & Uncultured Cyanobacterium (EU661291.1) & 100 & EU585900 & 3.6 & 6.0 & 1.8 & 3.2 & 2.7 \\
\hline & 14 & Uncultured Cyanobacterium (EU661291.1) & 98 & EU585902 & 2.7 & 4.8 & 2.6 & 3.1 & 14.4 \\
\hline & U1 & & & & 1.8 & - & - & - & 3.3 \\
\hline & U6 & & & & - & - & - & - & 3.5 \\
\hline & U8 & & & & 4.4 & 5.5 & 5.7 & - & - \\
\hline & U9 & & & & - & - & - & 1.1 & 1.9 \\
\hline & U11 & & & & - & - & - & - & 0.8 \\
\hline
\end{tabular}

Auto-HD: autochthonous gut microbiota of gibel carp cultivated at the high stocking density; Auto-LD: autochthonous gut microbiota of gibel carp cultivated at the low stocking density; Allo-HD: allochthonous gut microbiota of gibel carp cultivated at the high stocking density; Allo-LD: allochthonous gut microbiota of gibel carp cultivated at the low stocking density; Feed: microbiota of the diet

${ }^{\dagger}$ Relative abundance (RA, \%) was represented by the percentage of a specific band density to the total band density

Table 2: Representative of autochthonous and allochthonous bacteria or clones and their relative abundance (RA, \%) in DGGE fingerprint of gibel carp cultivated in high - and low density ponds, Eastern China.

The experiment lasted for 135 days. At the end of the feeding period, twelve fish with an average weight of $\sim 400 \mathrm{~g}$ (near the harvest size) were randomly collected from each pond and killed by a sharp blow on the head. All fish were individually sealed in sterile plastic bags, stored on ice at $-4^{\circ} \mathrm{C}$, and transported to the Key Laboratory for Feed Biotechnology of the Ministry of Agriculture, Feed Research Institute, Chinese Academy of Agricultural Sciences, Beijing, China within $6 \mathrm{~h}$. Six individual fish full of digesta were selected from each pond. Digesta 
Citation: Zhou Z, He S, Liu Y, Shi P, Yao B, et al. (2011) Do stocking densities affect the gut microbiota of gibel carp Carassius auratus gibelio cultured in ponds? J Aquac Res Development S1:003. doi:10.4172/2155-9546.S1-003

was gently squeezed out under sterile conditions as described elsewhere [16]. The autochthonous (adherent) and allochthonous (digesta) microbiota in the whole intestine of 6 pooled samples with identical weight were investigated. Analyses of pooled samples are a normal procedure used when investigating the gut microbiota by DGGE analysis of the 16S rRNA gene [16] to avoid inter-individual variations in the gut microbiota [16].

\section{DNA extraction, PCR amplification, and denaturing gradient gel electrophoresis (DGGE) analysis}

From each pond, genomic DNA from the bacterial communities of feed and the allochthonous and autochthonous fish gut microbiota were extracted as described by previous study [16,17]. Amplification of the $16 \mathrm{~S}$ V3 region and DGGE analysis were carried as described previously [17].

Gels were stained with ethidium bromide $\left(5 \mu \mathrm{g} \mathrm{mL}^{-1}\right)$ for 20 min, washed with deionized water and photographed with UV transillumination. Computer-assisted comparison of DGGE patterns was performed with BIO-ID++ gel analysis software (Vilber-Lourmat, Torcy, France). Relative abundance (RA, \%) was represented by the percentage of a specific band density to the total band density. The Shannon diversity index $H=-\sum \mathrm{Piln}(\mathrm{Pi})$ and Shannon equitability index $E_{H}=H / \ln (S)$ (where pi is the proportion of the ith band and $\mathrm{S}$ is the total number of visual bands) were calculated using spreadsheet software (V0.1, Microsoft Inc., Gardena, CA, USA) [18]

Cluster analysis was based on the unweighted pair group method using the arithmetic mean algorithm (UPGMA) as previously described by Liu et al. [17]. Similarity coefficients $\left(C_{s}\right)<0.60$ is regarded as significant difference, $0.60 \leq C_{\mathrm{s}}<0.80$ as marginal difference, and $C$ $\geq 0.80$ as similar.

\section{Sequencing of the $16 \mathrm{~S}$ rDNA V3}

The DNA fragments were excised and amplified using the primers without the GC clamp for sequencing [17]. After removing the unreliable sequences at the 3' and 5' ends, all sequences were subjected to similarity searches with the BLAST program [19]. Representative sequences were deposited in the National Center for Biotechnology Information (NCBI) (http://www.ncbi.nlm.nih.gov/) database under accession numbers EU585890-EU585896, EU585899-EU585903, EU585905-EU585910, EU585912-EU585913, EU585919-EU585920, EU585922-EU585925, EU585927-EU585931, and EU887825, respectively.

\section{Results}

\section{Analysis of the bacterial communities}

The 16S rDNA V3 DGGE fingerprints were used to profile the microbial communities of feed and in the gastrointestinal tract of gibel carp cultivated at high density (HD) and low density (LD) (Tables 1-3 and Figure 1$)$. Similar bacterial communities $\left(C_{\mathrm{s}}=0.83\right.$; Table 1$)$ were observed with respect to the autochthonous (Auto) and allochthonous (Allo) gut microbiota of gibel carp cultured in the HD pond (Auto-HD vs. Allo-HD). In contrast to these results, marginal difference $\left(C_{\mathrm{s}}=0.61\right.$; Table 1) was observed in the gut microbiota of gibel carp reared in the LD pond (Auto-LD vs. Allo-LD), and the allochthonous gut microbiota showed more bands (25 vs. 17 ), higher Shannon diversity index (3.026 vs. 2.437), and higher Shannon equitability index (0.824 vs. 0.673 ) (Table 3). The autochthonous gut communities of gibel carp in both ponds (Auto-HD vs. Auto-LD) were similar $\left(C_{\mathrm{s}}=0.86\right)$, but significant difference $\left(C_{\mathrm{s}}=0.58\right)$ existed between the allochthonous gut microbial communities (Allo-HD vs. Allo-LD). The allochthonous gut microbiota in HD pond (Allo-HD) showed lower visual bands (17 vs. $25)$ and Shannon diversity index (2.673 vs. 3.026$)$ than those indexes in $\mathrm{LD}$ pond (Allo-LD). The gut microbiota was significantly different $\left(C_{s}<0.60\right)$ compared to the community of the feed.

\section{Identification of bacterial species}

Actinobacteria, Proteobacteria, Firmicutes, Fusobacteria, Cyanobacteria, and some unclassified_bacteria taxa were detected in all samples investigated. However, 4 bands (band 6, 9, 11, and 27) showed identities less than $97 \%$ to known sequences and might represent new bacterial species (Table 2). Nine bands (band 1, 9, 10, 12, 14, 20, 30, 41 and 42) were identified in all the intestinal samples (Table 2). Band 29 and 36 were unique for fish cultivated in LD and HD ponds, respectively. Band 31 and 37 were only detected as allochthonous in fish cultivated in both ponds. Four DGGE bands (1, 2, 4 and 42) are found at higher abundance in both the allochthonous and autochthonous populations in the HD pond, while seven bands $(2,5,12,20,30,41$ and 42) are seen at higher levels in the LD pond. Seven bands (band 7, 17, $18,34,35$, U6 and U11) were only detected in the feed not in the fish.

\begin{tabular}{lccccc}
\hline Parameters & Auto-HD & Auto-LD & Allo-HD & Allo-LD & Feed \\
\hline $\begin{array}{l}\text { Numbers of } \\
\text { visual bands }\end{array}$ & 17 & 17 & 17 & 25 & 21 \\
$\begin{array}{l}\text { Shannon } \\
\text { diversity }\end{array}$ & 2.393 & 2.437 & 2.673 & 3.026 & 2.929 \\
index $(H)$ & & 0.673 & 0.852 & 0.824 & 0.891 \\
$\begin{array}{l}\text { Shannon } \\
\text { equitability } \\
\text { index }\left(E_{H}\right)\end{array}$ & 0.644 & & & & \\
\hline
\end{tabular}

Auto-HD: intestinal wall of gibel carp at the high stocking density; Auto-LD: intestinal wall of gibel carp at the low stocking density; Allo-HD: intestinal content of gibel carp at the high stocking density; Allo-LD: intestinal content of gibel carp at the low stocking density; Feed: diet.

TThe Shannon diversity index $H=-\sum p_{i} \ln \left(p_{i}\right)$ and Shannon equitability index $E_{H}=H$ $\ln (S)$ (where $p_{i}$ is the proportion of the ith band and $S$ is the total number of visual bands).

Table 3: Numbers of visual bands, Shannon diversity index ${ }^{\dagger}$ and Shannon equitability index of the bacterial communities in the GI tract of gibel carp cultivated in two saline-alkali ponds of Eastern China at different stocking density.

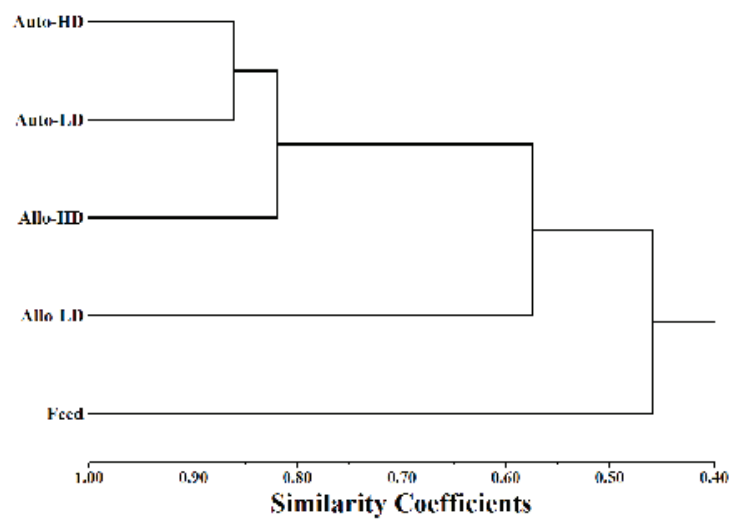

Auto-HD: intestinal wall of gibel carp at the high stocking density; Auto-LD: intestinal wall of gibel carp at the low stocking density; Allo-HD: intestinal content of gibel carp at the high stocking density; Allo-LD: intestinal content of gibel carp at the low stocking density; Feed: diet

Figure 1: The dendrogram of the 16S rDNA V3 PCR-DGGE fingerprints of the bacterial communities in the diet and the GI tract of gibel carp cultivated in two saline-alkali ponds of Eastern China at different stocking density. 
Among bacterial species of digesta and those associated to the gut wall of gibel carp in the HD pond (Table 2), six of them: band 1, 2, 4, 5, 27 and 42 were also detected in the feed.

\section{Discussion}

In the present study, Actinobacteria, Cyanobacteria, Firmicutes, Fusobacteria, Proteobacteria, and some unclassified bacteria were detected in the intestine of gibel carp.

Marginal differences $\left(C_{\mathrm{s}}=0.61\right)$ existed between the autochthonous and the allochthonous gut microbiota of semi-intensively cultured fish. These results are consistent with the results of Lutjanus sebae $(C<0.80 ;[20])$. However, in a poly-cultured pond of grass carp (Ctenopharyngodon idella), bluntnose black bream (Megalobrama amblycephala) and gibel carp, a $C_{s}$ value of 0.82 was reported between the autochthonous and allochthonous gut microbiota in gibel carp [21]. High similarity $\left(C_{\mathrm{s}}=0.83\right)$ was observed between the autochthonous and the allochthonous gut microbiota of fish cultivated in the HD pond, which indicate that the bacterial community between the allochthonous and autochthonous gut microbiota was not constant and was modulated by stocking density. Crowded conditions could impair the non-specific immunity of cultured fish [3], and the authors speculated that this could reduce adherence of the gut microbiota to the gastrointestinal (GI) wall, and enhance pathogen infection. Based on this hypothesis and the results of the present study we recommend that challenge studies be conducted to evaluate the relationship between stocking density and disease susceptibility.

Of the allochthonous and autochthonous gut bacteria detected in the HD pond, one band 1 showed high similarity to the anaerobic bacterium Cetobacterium somerae previously reported in the intestinal tract of freshwater fish [16]. Band 5 displayed $97 \%$ identity to a cyclic nitramine - degrading psychrophiloic bacterium (Fusobacteria) isolated from marine sediment [22]. In the present study, one band detected in the GI tract of LD fish showed high similarity to a Lactobacillales bacterium previously reported in a porcine bacterial culture collection (Hojberg and Jensen, unpublished data, national Center for Biotechnology Information (NCBI), http://www.ncbi.nlm. nih.gov/). One of the bands detected in the present study showed $99 \%$ identity to Lactococcus garvieae isolated and identified from rainbow trout (Oncorhynchus mykiss) cultured in Iran (Akhlaghi et al. NCBI, unpublished data). In a study of degrading of turfgrass (Kudo et al. NCBI, unpublished data) information of an uncultured Firmicutes bacterium (AB451793.1) was described. Our DGGE analysis showed that one band showed high identity to the uncultured Firmicutes bacterium.

The results from DGGE analysis displayed an autochthonous Lactobacillus panis in the GI tract of fish reared in the HD pond, showed high similarity to a bacterium first reported in the GI tract of chicken [23]. Among the allochthonous bacteria identified in gibel carp cultured in the HD pond, band 37 was most closely related to uncultured Eubacterium sp. (similarity $=99 \%$ ) previously isolated from chironomid larvae of Chironomus plumosus [24]. Clostridium paraputrificum first characterized from the forestomach of an eastern grey kangaroon (Macropus giganteus) [25] showed high similarity to band 22 detected in gibel carp reared in the $\mathrm{LD}$ pond. The anaerobic (band 6) and uncultured bacteria (band 4) detected in the present study showed high similarity to an anaerobic bacterium isolated from fish intestine (Sugita and Tsuchiya, NCBI, unpublished data), and the uncultured microorganism detected in aquatic bird feces [26], respectively. The higher abundance microbiota in $\mathrm{LD}$ and $\mathrm{HD}$ were 7 and 4, respectively, which was also modulated by stocking density. In the future, we will pay much attention to probiotics on intestinal microbiota at these stress conditions because of it contribute to intestinal microbial balance.

Based on the results obtained in the present study some general conclusions can be drawn: Actinobacteria, Proteobacteria, Firmicutes, Fusobacteria, Cyanobacteria, and some unclassified bacteria were identified in the gut of gibel carp. However, reduced intestinal bacterial diversity and the total number of higher abundance microbiota were noticed when the fish were cultured in the HD pond. Whether this finding has any effect on the efficacy or probiotics and prebiotics merits further investigations.

\section{Acknowledgments}

This work was supported by the National Natural Science Foundation of China (30972265) and the Key Program of Transgenic Plant Breeding (2009ZX08019020B).

\section{References}

1. Fisheries Bureau of Ministry of Agriculture (2010) China Fisheries Yearbook 2009. China Agriculture Press, Beijing, China. (in Chinese)

2. Danulat E (1995) Biochemical-physiological adaptations of teleosts to highly alkaline, saline lakes. Biochemistry and Molecular Biology of Fishes 5: 229-249.

3. Ellis T, North B, Scott AP, Bromage NR, Porter M, et al. (2002) The relationships between stocking density and welfare in farmed rainbow trout. J Fish Biol 61 493-531.

4. Ring $ø$ E, Birkbeck TH (1999) Intestinal microflora of fish larvae and fry. Aquacult Res 30: 73-93.

5. Spanggaard B, Huber I, Nielson J, Nielson T, Appel KF, Gram L (2000) The microflora of rainbow trout intestine: a comparison of traditional and molecular identification. Aquaculture 182: 1-15

6. He SX, Zhou ZG, Cao Y, Meng K, Shi P, et al. (2010) Effects of the antibiotic growth promoters flavomycin and florfenicol on the autochthonous intestinal microbiota of hybrid tilapia (Oreochromis niloticus $+\times 0$. aureus §). Arch Microbiol 192: 985-994.

7. Ringø E, Sperstad S, Kraugerud OF, Krogdahl A (2008) Use of 16S rRNA gene sequencing analysis to characterize culturable intestinal bacteria in Atlantic salmon (Salmo salar) fed diets with cellulose or non-starch polysaccharides from soy. Aquacul Res 39: 1087-1100

8. Al-Harbi A H, Uddin NM (2004) Seasonal variation in the intestinal bacteria flora of hybrid tilapia (Oreochromis niloticus $\times$ Oreochromis aureus) cultured in earthen ponds in Saudi Arabia. Aquaculture 229: 37-44.

9. $\mathrm{Hu} \mathrm{CH}, \mathrm{Xu} Y$, Xia MS, Xiong L, Xu ZR (2007) Effects of $\mathrm{Cu}^{2+}$-exchanged montmorillonite on growth performance, microbial ecology and intestinal morphology of Nile tilapia (Oreochromis niloticus). Aquaculture 270: 200-206.

10. Lv F, Huang J, Wang A (2007) Effects of alkalinity on the food consumption growth and survival of allogynogemetic crucian carp. J Anhui Agricul Sci 35 6789-6790 (in Chinese with English abstract).

11. He X, Li Z, Jia L, Lei W, Yang Y (1991) Effects of stocking density on growth and feed conversion of allogynogenetic crucian carp, Carassius auratus gibelio reared in cages, Lake Donghu, Wuhan. Acta Hydrobiologica Sinica 15: 375378. (in Chinese with English abstract)

12. Yao F, Zeng S, Yang Y, Peng K (2009) Effect of stocking density on nitrogen budget and energy budget of gibel carp. Journal of Anhui Agricultural University 36: 451-455. (in Chinese with English abstract)

13. Celli J, Knodler LA (2008) Of microbes and membranes: pathogenic subversion of host cell process. Cell Host Microbe 4: 514-518.

14. Pirarat N, Kobayashi T, Katagiri T, Maita M, Endo M (2006) Protective effects and mechanisms of a probiotic bacterium Lactobacillus rhamnosus agains experimental Edwardsiella tarda infection in tilapia (Oreochromins niloticus) Vet Immunol Immunopathol 113: 339-347.

15. Wang W, Zhou Z, He S, Liu Y, Cao Y, et al. (2010) Identification of the adherent microbiota on gills and skin of poly-cultured gibel carp (Carassius auratus 
Citation: Zhou Z, He S, Liu Y, Shi P, Yao B, et al. (2011) Do stocking densities affect the gut microbiota of gibel carp Carassius auratus gibelio cultured in ponds? J Aquac Res Development S1:003. doi:10.4172/2155-9546.S1-003

Page 5 of 5

gibelio) and bluntnose black bream (Megalobrama amblycephala Yih). Aquacul Res 41: e72-e83.

16. Sedgwick JD, Holt PG (1985) Induction of IgE-secreting cells and IgE isotypespecific suppressor $\mathrm{T}$ cells in the respiratory lymph nodes of rats in response to antigen inhalation. Cell Immunol 94: 182-194. http://www.ncbi.nIm.nih.gov/ pubmed/3160487.

17. Bullock G, Herman R, Heinen J, Noble A, Weber A, et al. (1994) Observations on the occurrence of bacterial gill disease and amoeba gill infestation in rainbow trout cultured in a water recirculation system. J Aquat Anim Health 6: 310-317.

18. Jiao J, Miao J, Zhang B, Liu J (1995) Summary of intensive culture of gibel carp in pond. China Fisheries (2), 21 (in Chinese).

19. Zhou Z, He S, Liu Y, Shi P, Huang G, et al. (2009) The effects of dietary yeast culture or short-chain fructo-oligosaccharides on the intestinal autochthonous bacterial communities in juvenile hybrid tilapia Oreochromis niloticus $9 \times 0$. aureus 0 . J World Aquacul Soc 40: 450-459.

20. Liu Y, Zhou Z, Yao B, Shi P, He S, et al. (2008) Effect of intraperitoneal injection of immunostimulatory substances on allochthonous gut microbiota of Atlantic salmon (Salmo salar L.) determined using denaturing gradient gel electrophoresis. Aquacul Res 39: 635-646.

21. Dethlefsen L, Huse S, Sogin ML, Relman DA (2008) The pervasive effects of an antibiotic on the human gut microbiota, as revealed by deep 16S rRNA sequencing. PLoS Biology 6: 2383-2400.

22. Altschul SF, Gish W, Miller W, Myers EW, Lipman DJ (1990) Basic loca alignment search tool. J Mol Biol 215: 403-410.
23. Zhou ZG, Shi PJ, He SX, Liu YC, Huang GX, et al. (2009) Identification of adherent microbiota in the stomach and intestine of emperor red snapper (Lutjanus sebae Cuvier) using 16S rDNA-DGGE. Aqual Res 40: 1213-1218.

24. Tsuchiya C, Sakata T, Sugita H (2008) Novel ecological niche of Cetobacterium somerae, an anaerobic bacterium in the intestinal tracts of freshwater fish. Lett Appl Microbiol 46: 43-48.

25. Zhao JS, Spain J, Thiboutot S, Ampleman G, Greer C, et al. (2004) Phylogeny of cyclic nitramine-degrading psychrophilic bacteria in marine sediment and their potential role in the natural attenuation of explosive. FEMS Microbiol Ecol 49: 349-357.

26. Lee CM, Sieo CC, Abdullah N, Ho YW (2008) Estimation of 16S rRNA gene copy number in several probiotic Lactobacillus strains isolated from the gastrointestinal tract of chicken. FEMS Microbiol Lett 287: 136-141.

27. Eller G, Deines P, Krüger M (2007) Possible sources of methane-derived carbon for chironomid larvae. Aquatic Microbial Ecol 46: 283-293.

28. Ouwerkerk D, Klieve AV, Forster RJ, Templeton JM, Maguire AJ (2005) Characterization of culturable anaerobic bacteria from the forestomach of an eastern grey kangaroo, Macropus giganteus. Letters in Appl Microbiol 41: 327 333.

29. Lu J, Santo Domingo JW, Lamendella R, Edge T, Hill S (2008) Phylogenetic diversity and molecular detection of bacteria in gull feces. Appl Environ Microbiol 74: 3969-3976.
This article was originally published in a special issue, Probiotic \& Prebiotic Applications in Aquaculture handled by Editor(s). Dr. Daniel L. Merrifield, University of Plymouth, UK; Prof. Zhigang Zhou, Chinese Academy of Agricultural Sciences, China 